\title{
O KITSCH ESTÁ CULT ${ }^{1}$
}

\author{
The kitsch is cult
}

Christina Maria Pedrazza Sêga ${ }^{2}$

\section{Resumo}

Com mais de um século de existência, a palavra kitsch ainda é confundida com brega. O conceito de kitsch ganhou uma dimensão que foi além do conceito de arte. Ele infiltrou-se em diversos segmentos de manifestações artísticas e estéticas apoiadas pela indústria cultural e pelos meios de comunicação de massa. Com isso, o kitsch passou a ditar a moda e padrões de comportamento voltados para a cultura urbana, presenciada e vivida no cotidiano de todos nós. Ele se consolidou na cultura de massa das grandes cidades e conquistou os caminhos da globalização.

Palavras-chave: arte, cultura, kitsch, mídia, consumo.

\begin{abstract}
The word kitsch has been still confused with the word cheesy, in spite of it having more than one century of existence. The concept of kitsch has gotten a dimension that goes farther than the concept of art. It has infiltrated in different artistic expressions that are supported by cultural industry and mass media. Therewith, the kitsch has begun imposing fashion and behavior patterns that are directed to the urban culture and to our day by day. It has consolidated in mass culture of big cities and conquered the paths of globalization.
\end{abstract}

Keywords: art, culture, kitsch, mass media, consumption.

\section{Resumen}

La palabra kitsch aun es confundida com cursi, mismo com más de um siglo de existencia. El concepto de kitsch ha ganado uma dimensión que superó el propio concepto del arte. El kitsch se infiltró en muchos seguimientos de manifestaciones

\footnotetext{
${ }^{1}$ Texto apresentado no IV ENECULT -Salvador (2008) e no INTERCOM -Natal (2008).

${ }^{2}$ Docente da Faculdade de Comunicação na Universidade de Brasília (UnB). Pós-doutora em Física Aplicada às Ciências Sociais - transdisciplinaridade. Doutora em Ciências da Comunicação pela Universidade Nova de Lisboa-PT. Tem artigos publicados no país e no exterior. Autora do livro $O$ Kitsch e suas Dimensões. Taguatinga DF: Casa das Musas, 2008. Contato: segach@unb.br
} 
artísticas y estéticas apoyadas por la industria cultural y por los medios masivos de comunicación. Con esto el kitsch pasó a influenciar la moda y patrones de comportamiento, direccionados hacia la cultura urbana, presenciada e vivida en nuestro cotidiano. El se consolidó en la cultura masiva de las gran ciudades y conquistó los camiños de la globalización.

Palabras-clave: arte, cultura, kitsch, medios de comunicación, consumo.

\section{INTRODUÇÃO}

Após severas contestações recebidas dos críticos de arte nos anos 60 e 70, o kitsch conquistou seu espaço no mercado de consumo da cultura de massa. Muito antes, a estética tinha como referência do mundo artístico as diretrizes da beleza e do equilíbrio. Com isso era possível conceituar o que deveria ser considerado arte em oposição ao que se poderia chamar de antiarte e nesta última classificação encontravase o kitsch. Hoje, a estética kitsch está presente na vida social das pessoas, na moda, no trabalho, na escola, entre jovens, adultos e crianças.

Oriundo do verbo alemão kitschen/verkitschen (trapacear, vender alguma coisa em lugar de outra), o termo kitsch adquiriu o significado de "falsificação" a partir de 1860. Porém, a palavra kitsch foi usada pela primeira vez na metade do século XX, na obra do sociólogo francês Edgar Morin (1987, p. 17) intitulada Esprit du temps.

Guimaraens \& Cavalcanti (1979, p. 9) encontraram outra possível origem para o kitsch, além de considerarem a etimologia alemã. Para esses autores há uma versão na língua inglesa, provinda da palavra sketch, significando esboço. Na segunda metade do século XIX, quando os turistas americanos queriam comprar uma obra de arte, a preço barato, eles pediam um sketch.

Apesar de mais de ter um século de existência, a palavra kitsch ainda apresenta alguma confusão em seu significado, sendo muitas vezes interpretada como sinônimo de brega. Entende-se que uma coisa é brega quando está relacionada ao mau gosto. Este conceito não se estende necessariamente ao kitsch. Mesmo que muitos atribuam ao kitsch o conceito de mau gosto, nem sempre esse mau gosto é evidente aos olhos do consumidor ou do indivíduo que faz uso do kitsch, principalmente se o objeto for uma réplica do original. Um típico exemplo é uma reprodução de um pintor famoso vendida na loja de um museu ou mesmo em frente a ele. De certa forma, pode-se 
considerar um objeto kitsch se ele apresentar uma ou mais das seguintes características: 1) imitação (de uma obra de arte ou de um outro objeto); 2) exagero na linguagem visual ou na linguagem verbal); 3) ocupação do espaço errado (um carrinho de pedreiro usado como jardineira em um canteiro de jardim); 4) perda da função original (uma garrafa de vinho usada como castiçal). Estas características foram elencadas pela autora deste texto em seu livro $O$ kitsch e suas dimensões.

\section{DO HORIZONTE DA ARTE}

O conceito de kitsch ganhou uma dimensão que extrapolou o próprio conceito de arte, fazendo outros percursos e se infiltrando em diversos segmentos de manifestações artísticas. A grande responsável por sua propagação foi a indústria cultural, que reproduzia em série as obras de arte para agradar o gosto da classe média burguesa, perdendo com isso o grau de autenticidade dessas obras.

Ultrajando os horizontes da arte, o kitsch veio percorrendo as artes plásticas, a arquitetura, decoração de ambientes, literatura, música, vestuário, publicidade, culinária e outros campos. Exemplos disso foram as obras do expoente artista dadaísta Marcel Duchamp, com sua obra A Fonte, de 1917, e, bem depois, já na década de 60, Andy Wahrol, com as obras Marilyn Monroe, de 1967, e Campbell Soup, de 1968, que hoje têm valores inestimáveis, a ponto de estarem incluídas entre as obras contemporâneas de "auras", diga-se de passagem.

Apoiado pelos meios de comunicação de massa, o kitsch atingiu a sociedade de consumo ou sociedade de massa à qual se destinam os produtos integrantes da cultura de massa. Ele tentou se encontrar na contracultura, mas se perdeu; passou a ser confundido com vanguarda, mas na verdade é seu substrato. Foi alvo de veementes críticas, principalmente pelos frankfurtianos, como Theodor Adorno, Max Horkheimer, Herbert Marcuse e Walter Benjamin, que contestavam a apropriação que certas tendências artísticas faziam da verdadeira arte estética, única e autêntica.Walter Benjamin (1980) um dos integrantes da Escola de Frankfurt, alegava que, na sua reprodução, a obra de arte perde a aura, isto é, perde sua própria autenticidade, com exceção da reprodução na fotografia e no cinema em que a reprodutibilidade é, desde o início, inerente a esses tipos de produção artística. Benjamin criou um antagonismo entre arte de aura e arte de massa, permitindo ao segundo tipo de arte, uma posição 
progressista, justificando que a arte de aura tinha sido relegada ao abandono. Esse seu posicionamento fez com que recebesse severas críticas de seus colegas frankfurtianos, Adorno e Horkheimer.

Ao lado da indústria cultural, o kitsch se alicerça na mídia, compondo nosso cotidiano por meio das novelas televisivas, da música e da publicidade. Além disso, é utilizado pela globalização como forma de democratizar a economia e a cultura. As regravações dos grandes sucessos de uma época, com novas interpretações ou ritmos musicais são considerados kitsch, assim como fusões de estilos, épocas e ritmos que, ao perderem suas características originais mediante as fusões, contribuíram para constituir o kitsch. No percurso cíclico e recursivo da moda e das tendências, particularmente do vestuário, a moda busca inspiração no passado para ditar as tendências futuras, chamando de "novidades" aquilo que fez parte de uma época. A cultura de massa, calcada na indústria cultural, consegue transformar arquétipos em estereótipos, estandartizando padrões da moda por meio da repetição desses modelos até serem consumidos massivamente pela sociedade.

O kitsch se define como panaceia psicossocial ao substituir a natureza autêntica do objeto em questão, na tentativa de solucionar uma frustração sócio-psicológica do seu usuário. Quem não gostaria de ter uma réplica da Mona Lisa em sua casa? Até mesmo uma estampa dessa obra pode surtir o mesmo efeito. O fato é que continua sendo apenas uma tentativa e nunca uma solução, propriamente dita, para resolver um problema psicossocial. Parece que isso não é o que realmente importa para quem faz uso do kitsch. O importante é "aparentar" e encontrar uma resposta viável para aquele problema, mesmo que superficial, usada como disfarce para encobrir tal frustração.

Porém, o kitsch também tem seu lado positivo na sociedade. Ele pode ser a solução ideal para um problema social. Os pneus velhos usados para fazer balanços em 'playgrounds' de escolas públicas são ótimas alternativas para baratear custos, além de evitar maiores complicações no caso de o balanço se chocar contra uma criança, desde que não acumulem água a ponto de contraírem a temível doença tropical conhecida por dengue.

Argumenta Moles (1975, pp. 28-29) que "o kitsch é mais uma direção do que um objetivo" e acrescenta que "há algo de kitsch no fundo de cada um de nós".

\section{RESISTINDO ÀS CRÍTICAS}


O kitsch se impôs glorioso na sociedade de consumo alicerçada pela indústria cultural que, por sua vez, obtém resultado com seus produtos por meio de formas estereotipadas mas expostas ao consumo como se fossem novas. Compreender o kitsch é antes de tudo entender o tripé que o sustenta: indústria cultural, meios de comunicação de massa e cultura de massa, termos que serão elucidados no interior deste texto. A relação estabelecida entre esses três elementos fortalece a sociedade de massa ou de consumo que tem como grande produto dessa relação, o kitsch. Teixeira Coelho (1981) analisa a indústria cultural tendo como respaldo a sociedade de consumo ou de massa. O referido autor relata em seu livro que há uma certa polêmica entre os estudiosos da cultura em relação à data do surgimento da indústria cultural. Uns dizem que foi com a invenção da imprensa. Outros consideram que isso ocorreu na segunda metade do século XIX, na Europa, com o teatro de revista, a opereta e o cartaz. Mas o mais adequado é entendê-la como consequência da Revolução Industrial, no final do século XVIII e tudo o que sucedeu, paulatinamente, esse episódio histórico. Teixeira Coelho caracteriza a indústria cultural como resultado de quatro fatores sócio-econômicos, melhor dizendo: revolução industrial, capitalismo liberal, economia de mercado e sociedade de consumo. Tudo isso acabou por criar a cultura de massa que, para Teixeira Coelho (1981, p. 28), melhor seria se fosse chamada por "cultura industrial" ou "cultura industrializada", já que é muito difícil conceituar o significado de "massa".

Quando processada pela indústria cultural, a arte resulta num produto de cultura de massa, consumido pela então já instituída sociedade de massa. Muitas vezes esse tipo de produto de consumo, típico da cultura de massa, nasce na própria massa, sendo por ela consumido. São exemplos disso alguns grupos musicais que surgiram fazendo um sucesso fulminante e desapareceram do mesmo modo que vieram, como foi o caso do grupo É o Tchan. Ainda na categoria de cultura de massa encontram-se as literaturas de bolso, distribuídas nas bancas de revistas e jornais com forte presença do kitsch mediante a identificação, aproximação e interação social no cotidiano das pessoas.

O caráter simbólico do kitsch está presente tanto em formas concretas como em formas abstratas. O que dizer de uma situação em que o interlocutor $A$, ao receber a visita do interlocutor $B$ em sua casa, recebe-o dizendo: 


$$
\begin{aligned}
& A \text { - Olá , quanto tempo! } \\
& B \text { - Estive viajando. } \\
& A \text { - Por onde? Por mares nunca dantes navegados? }
\end{aligned}
$$

Porém, o interlocutor $A$ poderia não ter certeza sobre a origem dessa frase, nem do seu autor e tão pouco preocupar-se com sua natureza, vulgarizando uma passagem memorável de Camões.

Tratando-se de imitação, o kitsch serve tanto à arte como aos objetos não artísticos. A satisfação em ter aquele objeto, mesmo sabendo muitas vezes que se trata de uma imitação, torna-se imensa por ele estar próximo ao objeto real. Com a aquisição desse objeto, o indivíduo percebe que estabeleceu uma relação de aproximação e de interação entre ele e a sociedade de consumo ou sociedade de massa. A relação de aproximação acaba adquirindo uma característica real para o seu usuário ao notar que estabeleceu uma aproximação consigo mesmo, satisfez seu ego e elevou sua autoestima, diminuindo sua insatisfação e até mesmo suas 'neuroses', lembrando aqui o pensamento de Morin (1987) sobre a sociedade de consumo. Por fim, tal aproximação integra o usuário à sociedade de consumo, também conhecida como sociedade de massa.

Quando Moles (1975, p. 44) menciona o "ideal da felicidade" e a "ausência de alienação" que os objetos oferecem ao indivíduo, isso equivale a entender a ideologia presente no cotidiano do burguês e, portanto, do indivíduo kitsch na sociedade de consumo. Moles (1975, p. 44) considera que ao se fazer uso de objetos ou atitudes kitsch certos valores são revelados no indivíduo inserido nessa sociedade de massa ou de consumo, tais como: 1) segurança; 2) afirmação de si próprio; 3) sistema possessivo; 4) gemütlichkeit - conforto em sentir-se à vontade; 5) ritual de um estilo de vida. Contudo, esses valores estão ligados ao que é considerado como ideologia do indivíduo na sociedade de massa, ou seja, sua visão e aspiração de mundo ideal.

\section{QUE CULTURA É ESSA?}

Os meios de comunicação de massa encarregam-se de passar a ideologia já filtrada pela indústria cultural para os seus receptores. Apesar de os meios de comunicação de massa terem seu surgimento com a invenção da imprensa, foi, contudo, com o advento da televisão que eles passaram a ser usados pela Indústria Cultural, 
responsável pela homogeneização da cultura e do conhecimento, bem ao gosto da sociedade de massa que se tornou fiel consumidora desse tipo de cultura, conhecida como cultura de massa.

A mídia se incumbe ora de elitizar, ora de popularizar um produto mediante os cenários televisivos e a linguagem publicitária. Especificamente sobre a Publicidade é que o estudo do kitsch merece uma atenção especial, visto que os consumidores são tentados, muitas vezes, a "comprar gato por lebre". Os apelos visuais e verbais embalam os sonhos do consumidor. Para entender melhor o gosto popular pelo kitsch, é necessário "levar mais longe a indagação sobre as raízes psicossociais do kitsch (...), penetrar mais fundo na geologia moral do homem massa e de seu antepassado cultural imediato - o burguês", observa José Merquior (1974, p. 13). Porém, antes de se falar sobre o processo e o lugar do kitsch na cultura e na sociedade, é oportuno neste momento conceituar cultura e suas subdivisões justamente para compreender por que o kitsch tornou-se cult.

Caldas (1986, p. 11) admite que o termo cultura é bastante abrangente, indo desde o significado de "cultivo" até "conhecimento científico", passando por conceitos de cultura erudita, cultura de massa e cultura popular. Herdamos do latim colere o significado de cultivo, aponta Caldas, sendo que "com os romanos, na Antiguidade, a palavra cultura foi usada pela primeira vez no sentido de destacar a educação aprimorada de uma pessoa, seu interesse pelas artes, pela ciência, filosofia, enfim, por tudo aquilo que homem vem produzindo ao longo da sua história" (Caldas, 1986, p. 11). Em grego, a cultura no sentido agrícola era conhecida como "georgia" e no sentido de educação como "paideia".

Após a Revolução Industrial houve uma crescente expansão social que proliferou a burguesia e, consequentemente, a "paideia" estava voltada para a "formação da educação" na opinião de Werner Jaeger, citado por Hannah Arendt (1972, p. 265). A "paideia" foi assimilada pelos romanos como sendo agricultura e culto religioso. Daí, então, os romanos escolheram a expressão "colere" para significar todo esse conjunto de sentidos. Arendt acredita que Cícero tenha sido o primeiro a usar a palavra "cultura" (colere) para designar "coisas do espírito e da alma”. Porém, os gregos já faziam distinção quanto aos objetivos de cultura.

Merquior adverte que: 
a 'paideia' não vive só em conexão íntima com a personalidade: vive também num estado superlativo de intencionalidade. De intencionalidade no sentido fenomenológico: uma cultura viva é sempre transitiva, está sempre orientada para 'objetos' autômatos e duráveis, que são os valores culturais. A 'intentio' da cultura faz com ela gravite em torno dos valores, atraída e norteada por eles.( Merquior 1974:17).

De outro modo, Merquior supõe que Cícero pode ter sido a primeira pessoa a empregar a palavra "cultura" com o significado de "intencionalidade". De uma forma geral, e particularmente no campo da linguística, compreende-se "intencionalidade" como "direcionalidade", distinção feita pelo linguista John Searle (1995). Para Abraham Moles (1975, p. 46) "há uma intencionalidade e uma relatividade no kitsch".

A palavra "cultura" é plena de armadilhas por ter muitos significados. Ela começa com um sentido geral, percorre os campos antropológico, psicológico e etnográfico e vai até os campos da estética e da ética, admite Morin (1977). Só no campo da antropologia ele detectou duas possibilidades significativas: a) cultura como organização, estruturação e programação social; b) cultura como linguagem, por traduzir todo aspecto semântico e intelectual de um povo. No campo da etnografia a cultura se contrapõe ao tecnológico e mantém os ritos, mitos e crenças, valores e normas de comportamento. No campo da sociologia a cultura tem sentido residual sobrando tudo que não se encaixa em outras áreas. No campo literário-artístico a cultura opõe o culto ao inculto. Morin (1977, p. 83) compreende, então, a "cultura como um sistema que faz comunicar - em forma dialética - uma experiência existencial e um saber constituído". Argumenta ainda que as diferenças dos conceitos de cultura estão na amplitude do sistema cultural, ou seja, dependendo do sistema a cultura pode ir desde a experiência vivida em sociedade até à cultura ilustrada do saber e do conhecimento estético, filosófico e científico, passando por esses códigos.

A cultura também é compreendida como um conjunto de caracteres sociais, políticos, étnicos, artísticos e religiosos, formas simbólicas de representar valores e crenças de um povo e de uma sociedade. Os padrões culturais dependem do tipo de organização existente nas sociedades. "Sem os padrões culturais, nenhuma sociedade, seja ela primitiva ou civilizada, teria chances de funcionar ou sobreviver (...). Sem cultura não haveria sistemas sociais da espécie humana e, consequentemente, o homem estaria impossibilitado de criar sua sociedade" (Caldas, 1986, p. 15).

Quando um sistema social é estratificado em diferentes classes econômicas há, dessa forma, diferentes culturas dentro desse mesmo sistema social. No caso de algumas 
sociedades, como é o caso da sociedade brasileira, além da estratificação econômica, há a diversidade étnica com seus credos e costumes responsáveis pela constituição do povo brasileiro. Isso faz com que exista pluralidade cultural no Brasil.

Por meio de um certo consenso estabelecido pelos sociólogos e estudiosos das sociedades e suas culturas, foi possível classificar, para uma melhor compreensão, a seguinte diferenciação de culturas: cultura erudita, cultura de massa e cultura popular. A cultura erudita é aquela que herdamos desde a Antiguidade até aquela que não foi processada pela Indústria Cultural e, nem consequentemente, divulgada pelos meios de comunicação de massa. Essa cultura inclui tanto os conceitos filosóficos como os artísticos. A noção de arte e de estética de que temos referência remonta aos padrões gregos e romanos da Idade Antiga e que depois foram recuperados durante o período do Renascimento. Os saberes matemático, artístico e filosófico encontraram na Idade Moderna as renovações científicas necessárias para o aprimoramento do conhecimento humano, enfim da alta cultura (high culture). Assegura Morin (1977, p. 83) que "no núcleo da cultura ilustrada há a inteligência que reivindica a propriedade cultural porque ela assegura sua criatividade". No processo de democratização ou popularização ocorre o que Dwight MacDonald (1962) denomina de midcult e, inversamente, no de elitização ocorre a masscult, embora alguns utilizem estes dois termos como sinônimos. Em Apocalípticos e integrados, Eco (1987, p. 76) se refere à obra de MacDonald reafirmando que na masscult erguem-se as manifestações de uma cultura de massa e a midcult é a corrupção da alta cultura.

$\mathrm{O}$ kitsch ora tende para o midcult ora para o masscult. O duet musical apresentado no Brasil entre Roberto Carlos e Pavarotti, na última década do século XX, seria um exemplo típico de midcult, sendo o cantor brasileiro um ídolo da média burguesia e Pavarotti, considerado elitista pelo próprio gênero musical, a ópera. No caso do masscult, pode-se citar o surgimento do estilo "new sertanejo". Este não tem as mesmas raízes que o "tradicional sertanejo", pois não traz os sonhos e os dissabores do agreste brasileiro, peculiares da cultura de raízes populares. Cultura de massa não é a mesma coisa que cultura popular e ambas se diferenciam substancialmente da cultura erudita.

A expressão cultura popular define um tipo de cultura produzida e consumida pelo próprio povo, de forma espontânea e distante das escolas e universidade. Está livre de influências massificantes como a cultura de massa, próprias da indústria cultural. 
Nesse tipo de cultura pode-se observar nitidamente as diferenças sociais, conforme aponta Waldenyr Caldas (1986), fato que já não acontece na cultura de massa. Afirma Caldas que a "cultura popular pode ser um dos pontos de apoio das transformações sociais".

Cultura de massa é o resultado da produção de ideias e produtos filtrados pela indústria cultural, divulgados e distribuídos em massa para a sociedade de consumo. São incluídos nesse universo cultural a moda, os ídolos da música, a arte representada pela música, literatura e artes plásticas, esporte e lazer. Todos apoiados fortemente pela mídia, ou seja, pelos meios de comunicação de massa, cujos maiores detentores de opinião pública são a televisão, a imprensa e o rádio. Eles são capazes de ascender ou destituir com a mesma facilidade e rapidez, um ídolo da política, da música, das telenovelas e do esporte, enfim, um ídolo do público.

A indústria cultural, apoiada pela mídia, propaga a cultura de massa e transforma arquétipos em estereótipos, estandartizando padrões da moda por meio da repetição desses modelos até serem consumidos massivamente pela sociedade. Para o desgosto dos críticos da indústria cultural, seguir essas tendências é um sintoma de alienação. Para outros segmentos da sociedade, não segui-las também se torna alienante por se considerarem fora do contexto social no qual estão inseridos e alienados às mudanças. A cultura de massa é um elemento facilitador no momento em que coopera para a integração do indivíduo à sociedade de massa. Em geral, a principal preocupação dos teóricos está no fato de a cultura de massa homogeneizar os valores culturais e estéticos, tornandos-os impessoais.

\section{CRIATIVO E PRAGMÁTICO}

O kitsch pode ser criativo por várias razões. Por ser alternativo, econômico, sugestivo, oportuno, funcional, além de possuir uma gama de adjetivos que poderíamos atribuir-lhe. Ele complementa uma ideia, dá o toque desejado a um ambiente, porém nunca é original na sua criatividade, nem na sua essência. $\mathrm{O}$ seu aspecto alternativo acaba por resultar em uma solução adequada a uma situação ou a um problema em questão. Por mais exigentes e por mais conhecedores de estética da arte que formos, é quase impossível não sermos e não termos um pouco de kitsch em cada um de nós. Ainda mais quando este é a solução "perfeita" para um problema imediato, além de 
econômico e prático, apresentando um resultado ou um efeito tão bom ou até melhor que o próprio original. Os especialistas dos cenários das telenovelas, do teatro, do cinema e até mesmo dos desfiles de carnaval bem sabem disso. $\mathrm{O}$ efeito do kitsch é surpreendente. O papel alumínio que imita prata, as plantas de plástico que imitam as naturais, as frutas artificiais na fruteira da cozinha e assim por diante.

Por meio de fatos ou acontecimentos notamos que a moda é kitsch quando ela tenta resgatar uma época ou um modismo que fez sucesso em determinado ano ou década. Os "remakes" cinematográficos, de telenovelas e as regravações musicais são exemplos típicos do kitsch. Muitos jingles para campanhas políticas se apropriam de músicas de sucesso, com modificação da letra, adequando-as à proposta do candidato em questão. A moda e os modismos urbanos veiculados pela mídia impulsionam os jovens, os adultos e as crianças para o consumo do kitsch.

Mesmo não sendo original, por não partir de uma única origem e não ter uma referência única, o kitsch pode ser criativo. Certa vez, um garoto de 12 anos enviou sua ilustração para o caderno infantil de um periódico local. Era um desenho de um homenzinho mirrado, com bigodes estilizados de Salvador Dalí, lembrando a logomarca da Nike. De forma inconsciente, esses foram os efeitos subliminares da publicidade, apoiados pela mídia, pois a referida marca está fortemente implantada no imaginário da sociedade de consumo de maneira globalizada, fazendo com que seus usuários tenham enorme devoção à marca Nike, quer por fidelidade, quer por ideologia do status que o produto oferece a eles. O kitsch ali criado (houve deslocamento da logomarca da Nike para compor os bigodes do pintor surrealista) valeu como uma alusão à sociedade de massa ou mesmo uma crítica debochada ao consumo exacerbado de marcas que denotam status, mesmo que essa manifestação do garoto tenha sido inconsciente ou sob efeitos subliminares da mídia.

Para Moles, uma coisa pode ser kitsch num lugar e funcional no outro. Ele cita o exemplo em que um conjunto de candelabros pode ser kitsch em Paris e não ser na Itália, já que este país teve sérios problemas de eletricidade em determinada época. Na verdade, o kitsch é kitsch em qualquer lugar, não importa a problemática de cada local. É no aspecto "funcionalidade" que este texto discorda de muitos críticos que analisaram o kitsch até então. A maioria diz que o kitsch não é funcional; mas ele é sim. Sua característica universal de funcionalidade é inerente a ele, já associada ao seu valor de uso. O que ocorre é que ele muda da função original para uma segunda função 
totalmente diferente da primeira e seu uso vai depender do grau de utilidade que ele possa ter em determinada situação. Por exemplo, se estivermos numa fazenda, à noite, e precisarmos de iluminação (caso falte eletricidade), poderemos nos servir de umas garrafas vazias como castiçais para as velas. Numa sociedade como a de hoje, sujeita a alterações econômicas, que se refletem na bolsa de valores e nas moedas cambiais, o funcional deverá desempenhar, no mínimo, duas funções. Um exemplo disso, citado por Abraham Moles (1975, pp. 205-216) em seu livro $O$ Kitsch, é uma peça que desempenha três funções: saca-rolha, abridor de latas e de garrafa em um único objeto. O kitsch não é antifuncional. Ao contrário, ele acaba adotando uma característica pragmática e utilitária. A universalidade se mantém pelo caráter bifuncional ou até mesmo plurifuncional. Vejamos, por exemplo, os gadgets (objeto engenhoso), miniaturizados, com o intuito de realçar sua praticidade funcional. Um chaveiro-relógio, minidespertador, com função de porta-retratos e chaveiro ao mesmo tempo, uma caneta termômetro em miniatura.

O kitsch, então, "surgiu como reação a normas rígidas que tiveram origem no funcionalismo", consideram Guimaraens e Cavalcanti (1979, p. 27). Pode-se ainda acrescentar as 'imitações' como funcionais para determinada situação em que o objeto original não é viável. Por exemplo, réplica de objetos raros em alguma exposição por medida de segurança contra possível furto ou violação de tal relíquia. Outro tipo de situação é a dos cenários para apresentação de peças teatrais, filmes ou algum tipo de encenação pública, como os desfiles de Carnaval, ou mesmo o uso de plantas artificiais na decoração de ambientes de telenovelas e na ornamentação de aquários, devido à fácil manutenção desses espaços.

\section{SÉCULO XXI: O KITSCH NAS CULTURAS URBANAS GLOBALIZADAS}

Mas cabe aqui uma pergunta: o que dizer dos valores culturais hoje em dia?

É sabido que estamos vivendo, em pleno século XXI, uma cultura efêmera, transitória, mas que não perde seu caráter de "intencionalidade", que se orienta para objetos e pessoas inseridas numa cultura de massa renovável a todo momento. Toda "intencionalidade" possui uma "direcionalidade", lembrando aqui o ponto de vista de Searle (1995). E o kitsch segue uma "intencionalidade", uma "direcionalidade" voltada 
para a ideologia da sociedade de massa ou de consumo. Que ideologia é essa, senão a da globalização e a do multiculturalismo?

Diante de propostas unificadoras vindas do mercado econômico mundial, a sociedade de consumo busca enquadrar-se nessas tendências mundiais, globalizando a economia, a cultura, as tendências e o gosto em geral. Uma grande massificação cultural e estética está presente na sociedade tecnológica e globalizada (Sêga, 2006). Isso evidencia que o kitsch também pode ser encontrado fora do âmbito da arte. A moda e a culinária são exemplos típicos de uma economia globalizada. Há, dessa forma, um deslocamento geográfico e cultural próprio da globalização. Ocorre a presença do kitsch porque, para atender ao mercado consumidor, o produto exportado precisa se adequar à cultura local do mercado consumidor, perdendo assim, na maioria das vezes, suas características originais, quer na aparência, quer na maneira de utilização.

Além da perda da identidade nacional dos produtos exportados, resultado de um consenso comum de cada bloco econômico, os países importadores acabam por perder suas características particulares ao adotarem determinados produtos. Dessa maneira, o kitsch pode ser considerado uma interferência cultural com finalidades comerciais.

\section{CONCLUSÃO}

O kitsch hasteou bandeiras contrárias à elite dirigente. Excluiu a aura do iluminismo estético, ganhando espaço áureo na cultura de massa. Nela consolidou-se, proliferou-se, globalizou-se. Pleno de liberdade, o kitsch transitou pela contracultura, mas nela não se encontrou. Recebeu vários nomes: 'midcult', 'ready-made', 'gadget', etc. Despiu-se de toda pureza e originalidade e tornou-se objeto de desejo de vários consumidores. Mas há quem escolha o kitsch por razões contestatórias ou mesmo por simples deboche.

O lado cult do kitsch foi mencionado por Santos (2004) ao analisar as artes plásticas e a literatura no Brasil e na América Latina. No Brasil, o Tropicalismo de Gilberto Gil e Caetano Veloso marcou o kitsch musical. O kitsch veio para ficar por tempo indeterminado. Passou a ser considerado cult e chic, ao mesmo tempo em que é uma panaceia para os problemas sociais, econômicos e culturais da sociedade de consumo. 


\section{REFERÊNCIAS BIBLIOGRÁFICAS}

ARENDT, H . Entre o passado e o futuro. São Paulo: Perspectiva, 2003.

BENJAMIN, W. "A obra de arte na época de suas técnicas de reprodução", in Textos escolhidos. São Paulo: Abril Cultural, 1980.

CALDAS, W. O que todo cidadão precisa saber sobre cultura. São Paulo: Global, 1986.

ECO, U. Apocalípticos e integrados. São Paulo: Perspectiva, 1987.

GUIMARAENS, D. e CAVALCANTI, L. Arquitetura e kitsch. Rio de Janeiro: FUNARTE, 1979.

MACDONALD, D. "Masscult \& Midcult", in Against the american grain. New York: Random House, 1962.

MERQUIOR, J. G. Formalismo e tradição moderna. São Paulo: Editora Forense, 1974.

MOLES, A. O kitsch. São Paulo: Perspectiva, 1975.

MORIN, E. Cultura de massa no século XX - o espírito do tempo. Vol I e II, Rio de Janeiro: Forense-Universitária, 1977; 1987.

SANTOS, Lídia. O kitsch tropical. Madrid: Iberoamericana, 2004.

SEARLE, J. Intencionalidade. São Paulo: Martins Fontes, 1995.

SÊGA, C. M.P. O kitsch e suas dimensões. Taguatinga (DF): Casa das Musas, 2008. . A estética na sociedade globalizada e tecnológica, in Revista Comunicação e Sociedade. São Paulo: Universidade Metodista, Ano 28, N ${ }^{0}$ 47, 2006, p. 85-97. TEIXEIRA COELHO, J. O que é indústria cultural. São Paulo: Brasiliense, 1981.

Artigo recebido em 17/2/2010.

Aprovado em 7/4/2010. 